\title{
TEChNiCAL Diagnostics in The PAPER INDUSTRY
}

\author{
Radoslav Krehel', Marek Kočiško \& Peter Poór
}
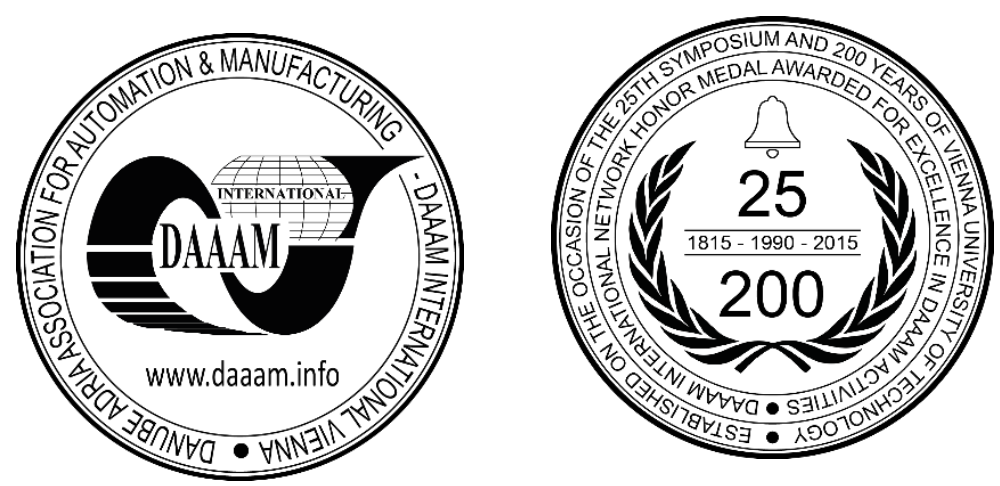

This Publication has to be referred as: Krehel, R[adoslav]; Kocisko, M[arek] \& Poor, P[eter] (2016). Technical Diagnostics in the Paper Industry, Proceedings of the 27th DAAAM International Symposium, pp.0775-0784, B. Katalinic (Ed.), Published by DAAAM International, ISBN 978-3-902734-08-2, ISSN 1726-9679, Vienna, Austria DOI: $10.2507 / 27$ th.daaam.proceedings. 112

\begin{abstract}
Sample application article offers diagnostic sensor networks. It is shown how it is possible to diagnose production facilities that provide a network containing diagnostic sensors. Comprehensive and systematic view of the use of vibration diagnostics in the factory. Recovery of used vibration diagnostics and technical equipment was carried out on the printing machine Heidelberg Speedmaster directly in active operation of the particular stationery company. Based on the results of measurement of vibration (vibration) deposits are processed and the results are optimal solutions forward.
\end{abstract}

Keywords: Lathe processing; mechanical vibration; vibration acceleration amplitude; frequency; frequency spectrum.

\section{Introduction}

To detect impending defects or equipment failures, there are several methods and procedures. One of these methods is one of the main parts of the technical diagnostics and vibrodiagnostics, which deals with measuring and assessing vibration, or mechanical vibration devices diagnosed eg. electrical rotating machine. Based on the results obtained by measuring and analyzing vibration, we are able to prevent or at least delay the failure to diagnose the machine. This is a very impor-tant especially if it is an impor- tant in the manufacture of equipment whose failure could cause major losses and problems for the production. Some companies push the diagnostic data a step further and create forecasts - those opposed to the trapping law, pump failure, entire production operation and tweak it for longer uptime and greater effi ciency. Now we get more information about the network. Branches operate your business have come to this data only to determine the problem. However, currently operating more and more focus on the forecasts in order to eliminate problems. Machinery and equipment provide more information and utilization forecasts for possible defects detected and removed earlier. In the past it was considered a single task readiness and operational capability to produce at minimum cost optimal. Today, more and more manufacturing companies realize that maintenance has an impact on all areas of business risk and efficiency. Definitely affects the personal security, energy efficiency, product quality and meet customer needs [1, 2]. Vibrodiagnostiky main task is to determine the moment when the bearing is the end of their life. Bearings are final and life be destroyed, even if the subsequent installation and maintenance were in order. Thus, the diagnosis is not that we save the deposit, but to ensure reliable operation of equipment $[3,4]$. In addition to natural wear of bearings such as find hidden errors, which then can cause rapid wear of bearings, or transported to a critical state, or sudden, unexpected failure. When the diagnosis is to determine the following errors: wear of bearings, release bearings, although people shaft, unbalance, incorrect setting transfer belt, bent shaft, free teeth disorders, resonance, and so on [5, 6, 7]. 


\section{Measurement and analysis of technical condition of the paper printing machine brand He Delberg}

The diagnostic measurements in a firm in which the measurement was carried out was to find technical condition and wear of moving parts printing machine He Delberg (figure 1).

\subsection{Analysis of problems and selection of the optimal solution}

The importance of technical diagnosis is high, despite its insufficient attention to even in many manufacturing operations. In tandem with adequate maintenance, but many times can extend the life of machinery and save money for frequent repairs of defects. Slowly it improves and the number of businesses that use a serious diagnosis is increasing. The technical diagnosis is an important part of maintenance of machinery and equipment. What types of diagnostics are used and what they have in common, or what are the differences? There are many types of diagnostics, but have a common goal which is to consider operating without dismantling the state apparatus, machinery or node. The challenge is to determine the functional status of the device based on the results vibrodiagnostics $[8,9,10]$.

\subsection{Conduct diagnostic measurements}

The company was conducted to measure the printing machine He Delberg.
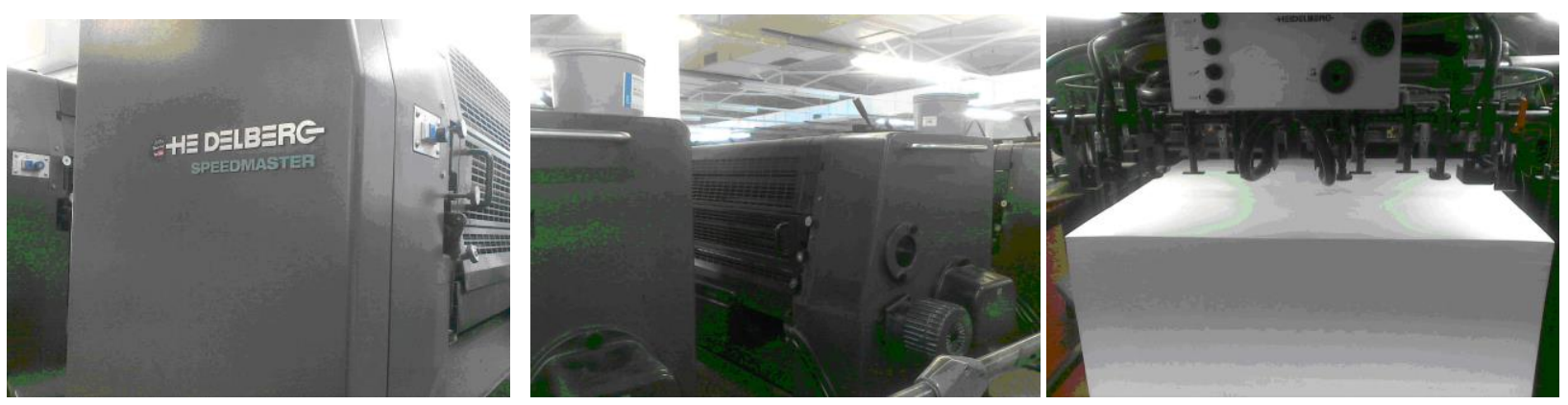

Fig. 1. Printing machine He Delberg, sample main propulsion printing machine and preview print one sheet

The measurement was designed to assess the vibration of the main printing machine operator (figure 1). The engine manufacturer, Siemens. Machine was diagnosed 13 years but still bearing the original [11, 12]. The measurement was necessary to define a revolution that is known as a rotary wheel of the machine, but takes into account the number of printed sheets (figure 1). One wheel of the machine is printing a single sheet $[13,14,15]$.

\subsection{Measurement procedure}

As a diagnostic tool measuring points were selected in two places:

- measuring point is located on the main drive at the front

- measuring point is located on the main drive behind

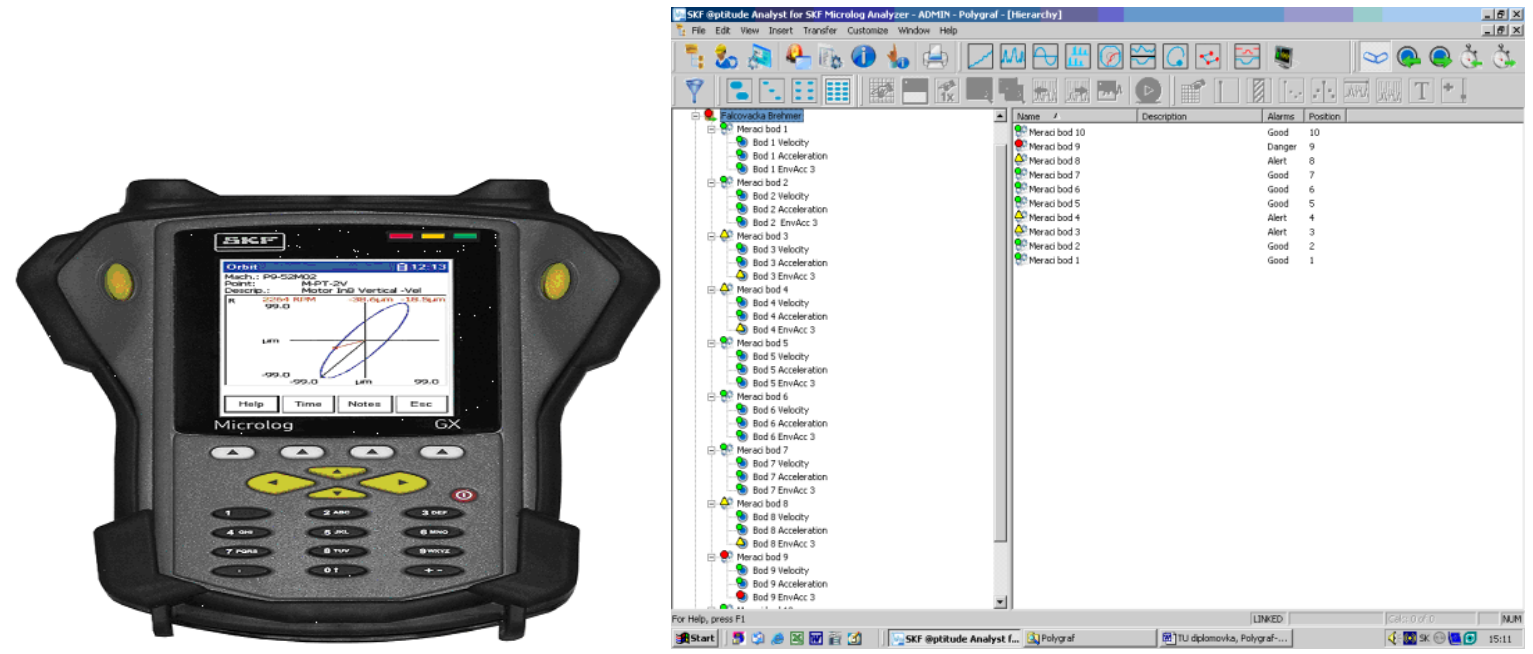

Fig. 2. Measuring device Microlog GX-S and create a database of measuring a computer program AptitudeAnalist for SKF microlog analiser 
Using vibration diagnostic instrument was measuring device microlog GX-S (figure 2). Frequency spectra were analyzed using software AptitudeAnalist. The first task was to create a database of measuring a computer program AptitudeAnalist for SKF microlog analiser (figure 2), where the navolené number of measurement points, as well as signal processing method, or setting alarms. Subsequently, the data were uploaded into the measuring device. Then the vibration measurement itself took place $[16,17,18]$.

\subsection{Data collection}

The printing machine was selected two measuring points (figure 3). In each of these points was measured vibration velocity (Velocity), vibration acceleration (Acceleration) and envelope acceleration (EnvAcc) depending on the speed. Measurements took place in the value of speed $3000 \mathrm{rpm} 8000 \mathrm{rpm}$ and 12,000 rpm [19, 20].

\section{A graphic representation of the vibrations of certain points and analysis}

Measurement of vibration diagnostic signals to the printing machine at $3000 \mathrm{rpm}$.

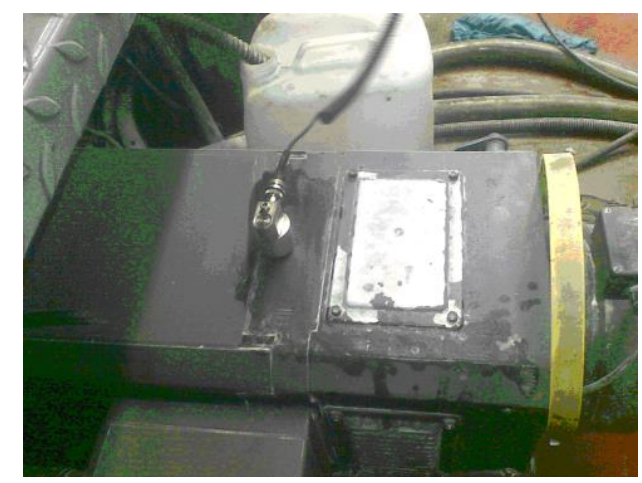

Fig. 3. Demonstration of the practical implementation of diagnostic measurements of the vibration signal in the first measuring point

Measurement results are displayed in graphs in figures (figure 4 to figure 15).

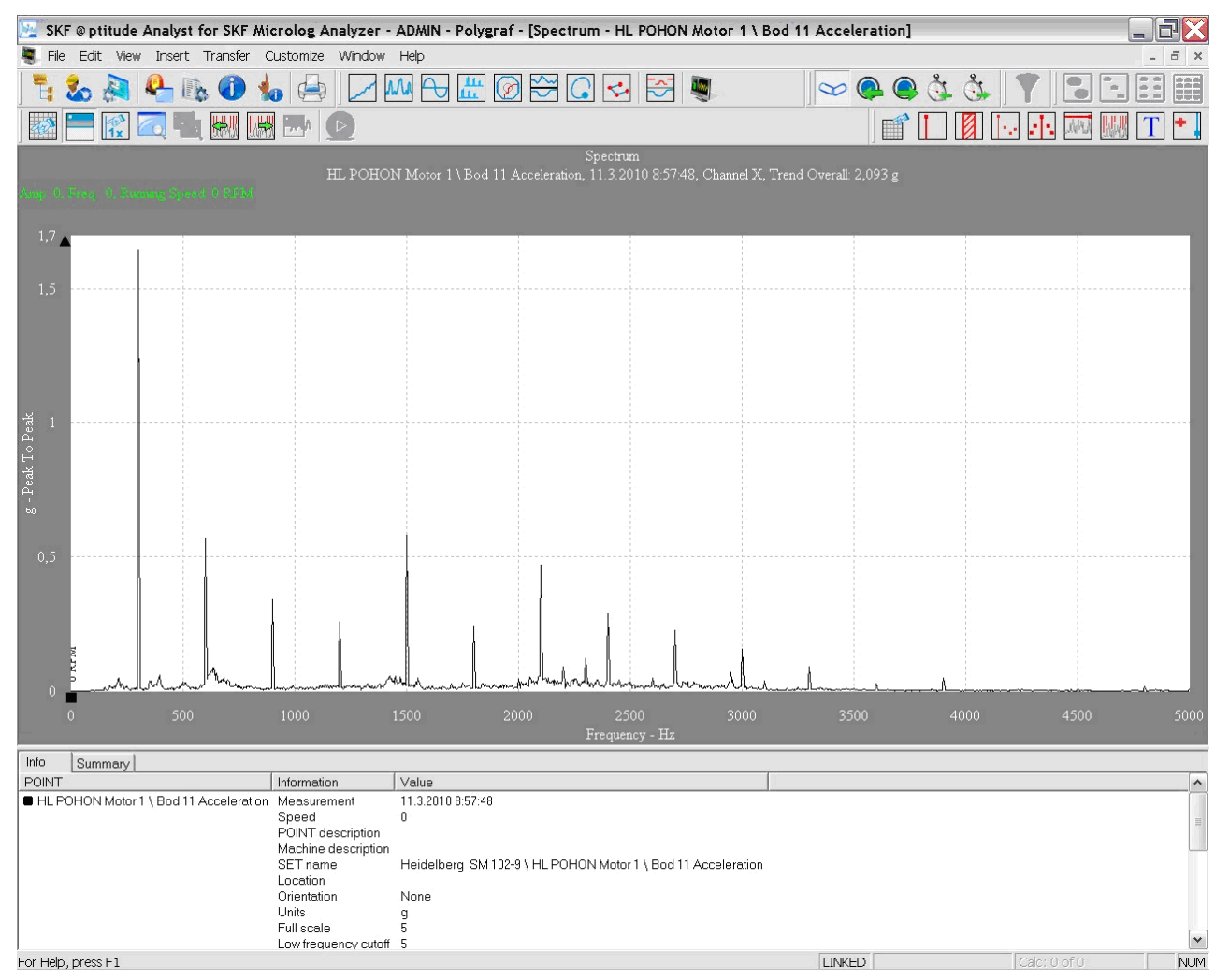

Fig. 4. Spectrum measured vibration diagnostic signals in the first measuring point at $3000 \mathrm{rpm}$ 


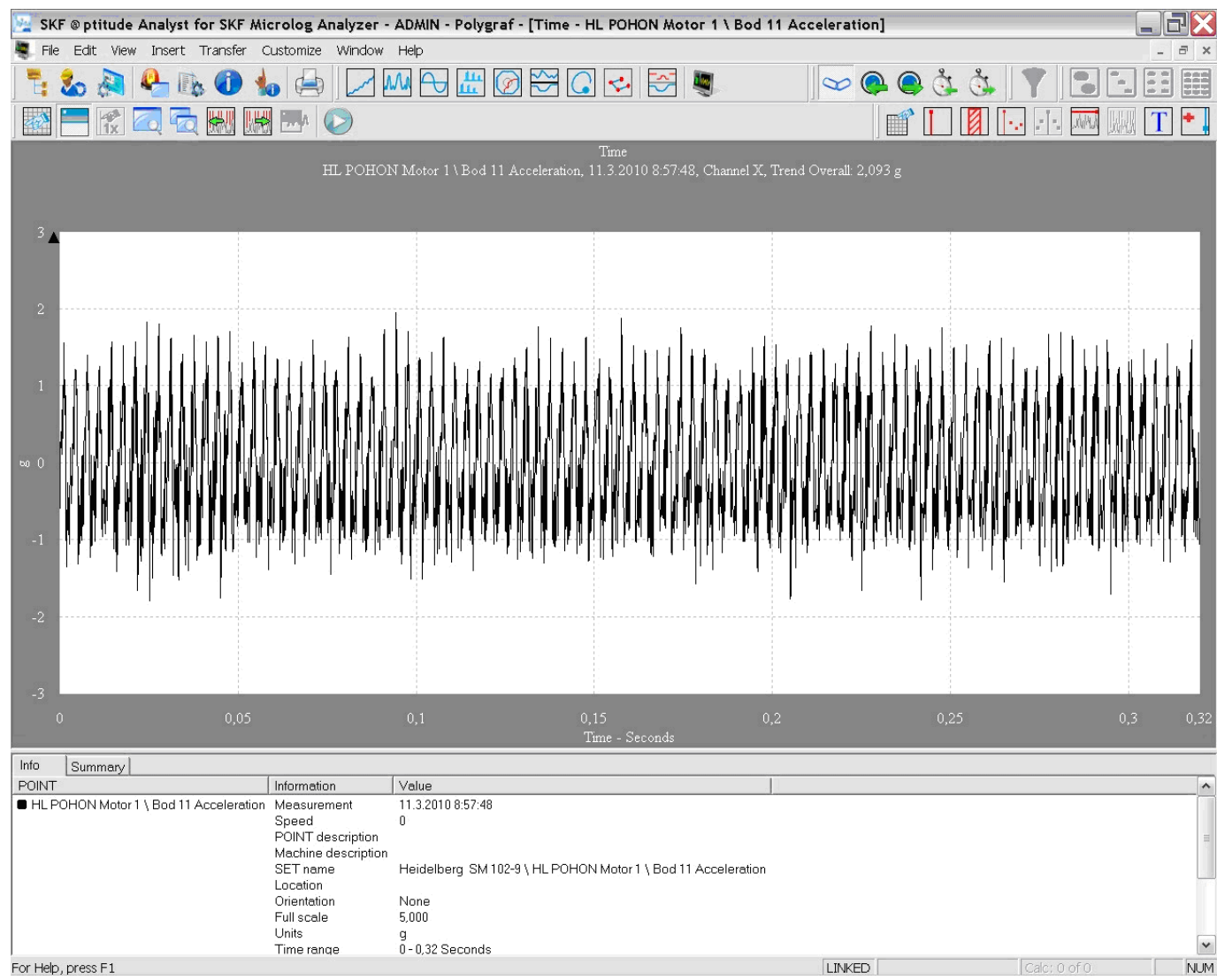

Fig. 5. Time record first measuring point at $3000 \mathrm{rpm}$.

Measurement of the first measuring point at $8000 \mathrm{rpm}$ :

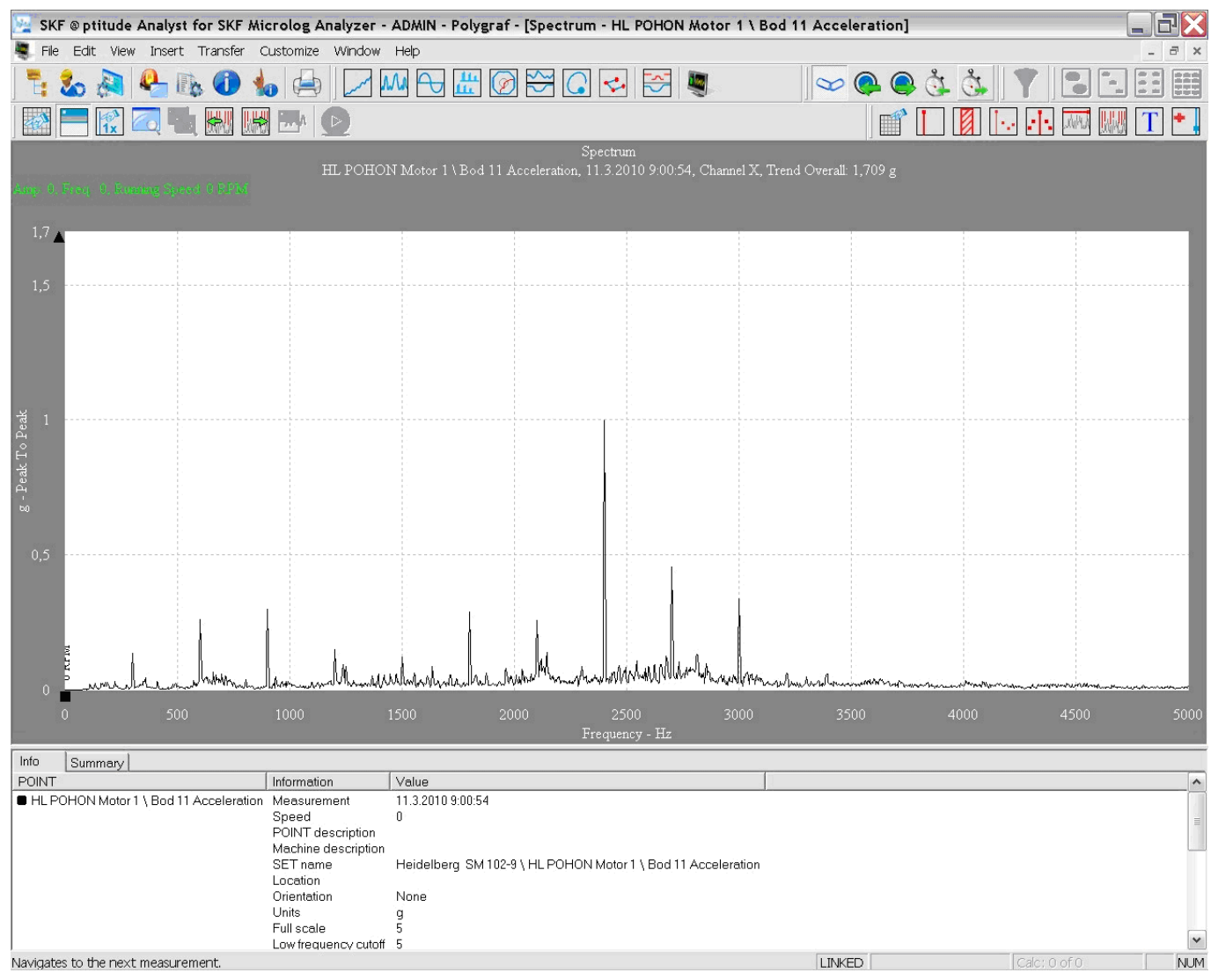

Fig. 6. Spectrum measured vibration diagnostic signals in the first measuring point at $8000 \mathrm{rpm}$ 


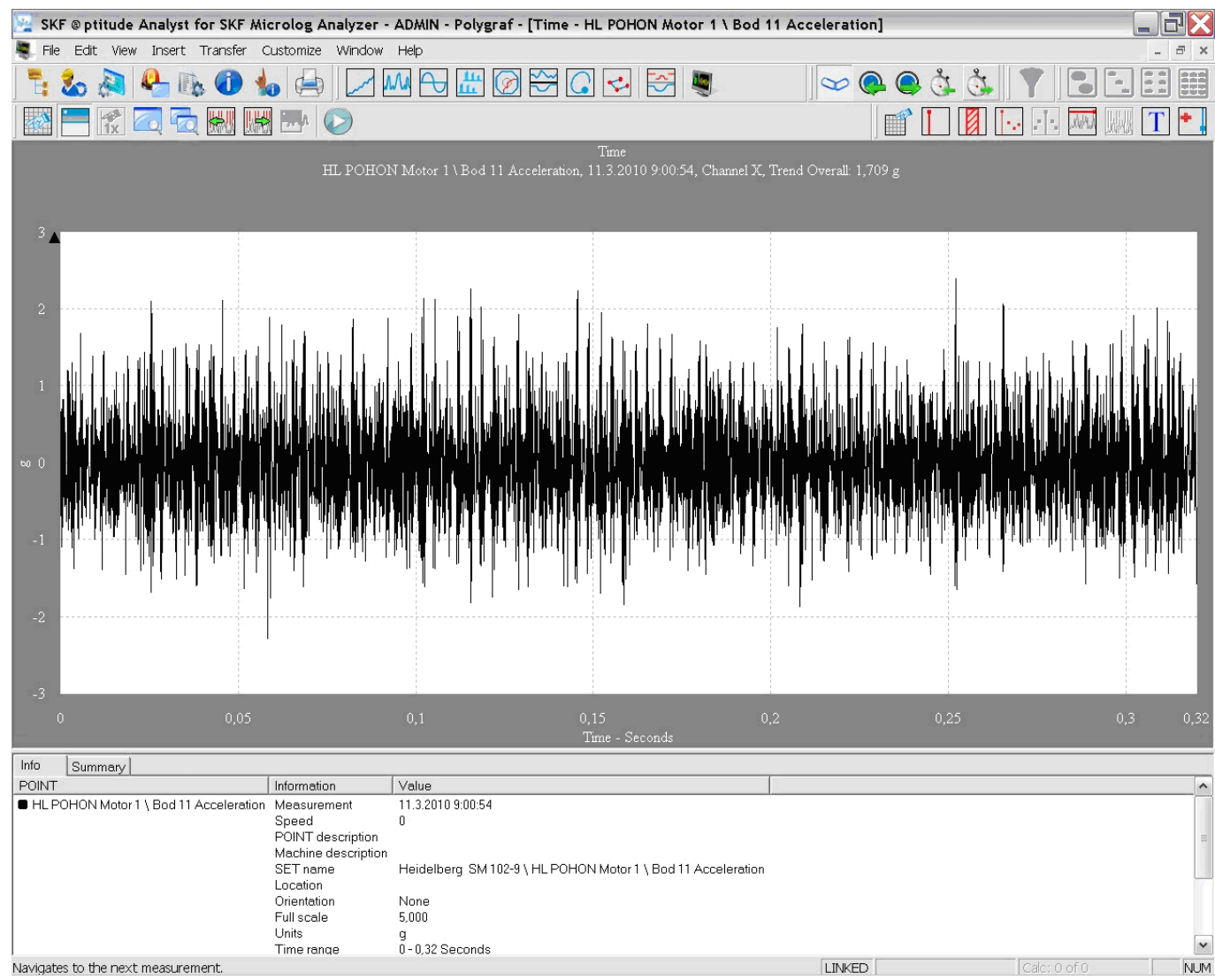

Fig. 7 Time record first measuring point at $8000 \mathrm{rpm}$.

Measurement of the first measuring point at $12000 \mathrm{rpm}$ :

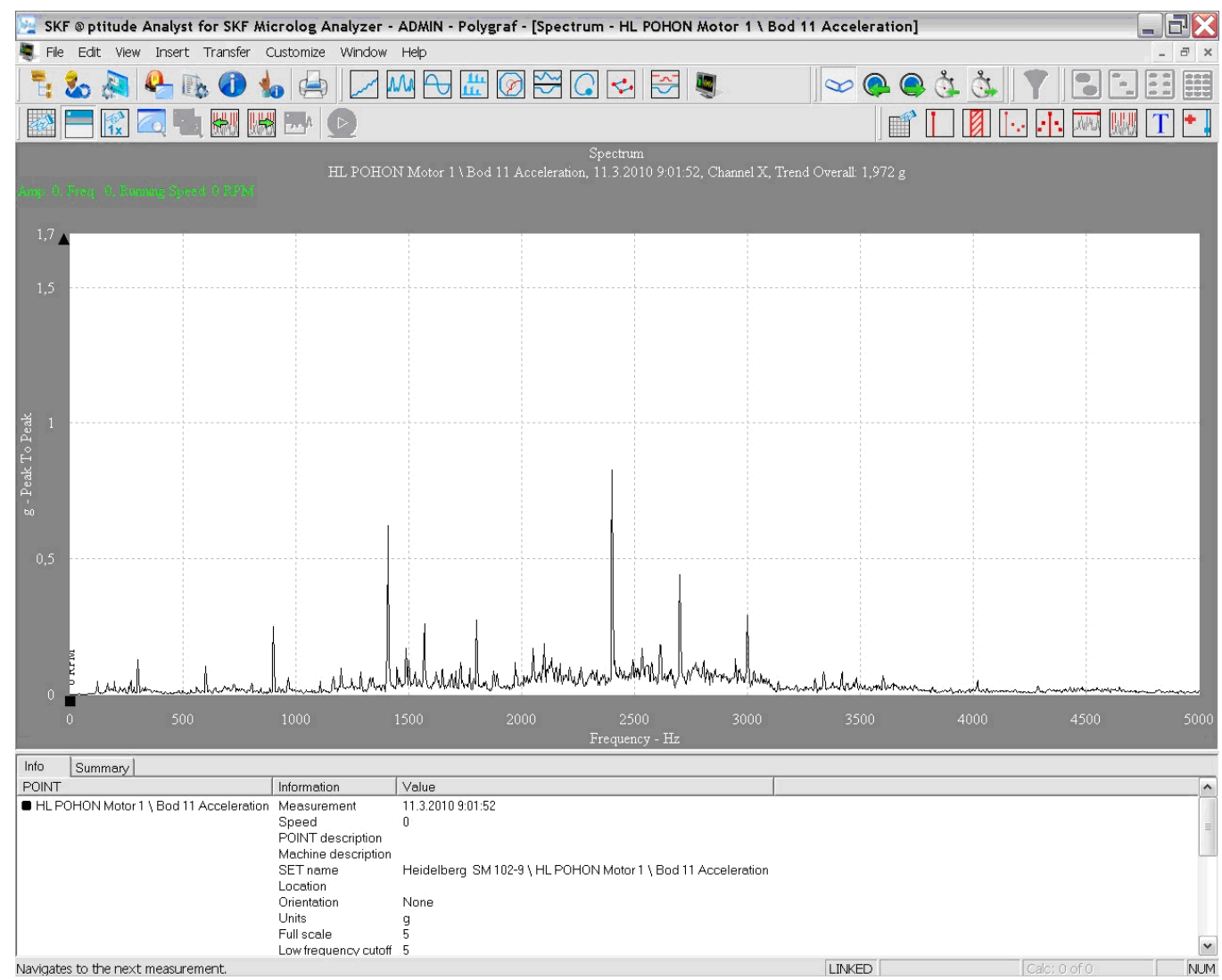

Fig. 8 Spectrum measured vibration diagnostic signals in the first measuring point at 12,000 rpm 


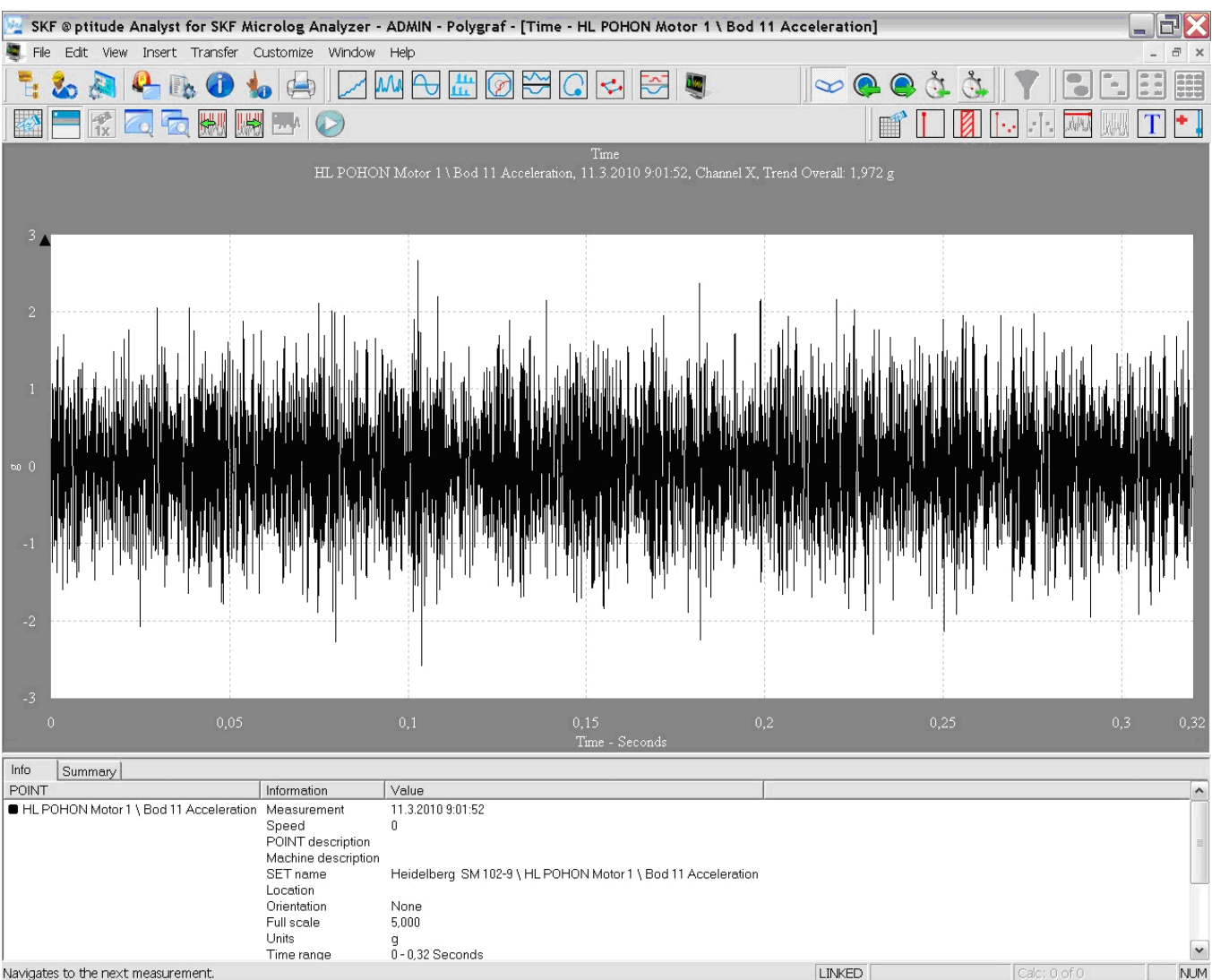

Fig. 9 Time record first measuring point at 12,000 rpm

Processed measurement results of the second measuring point printing machine at $3000 \mathrm{rpm}$ :

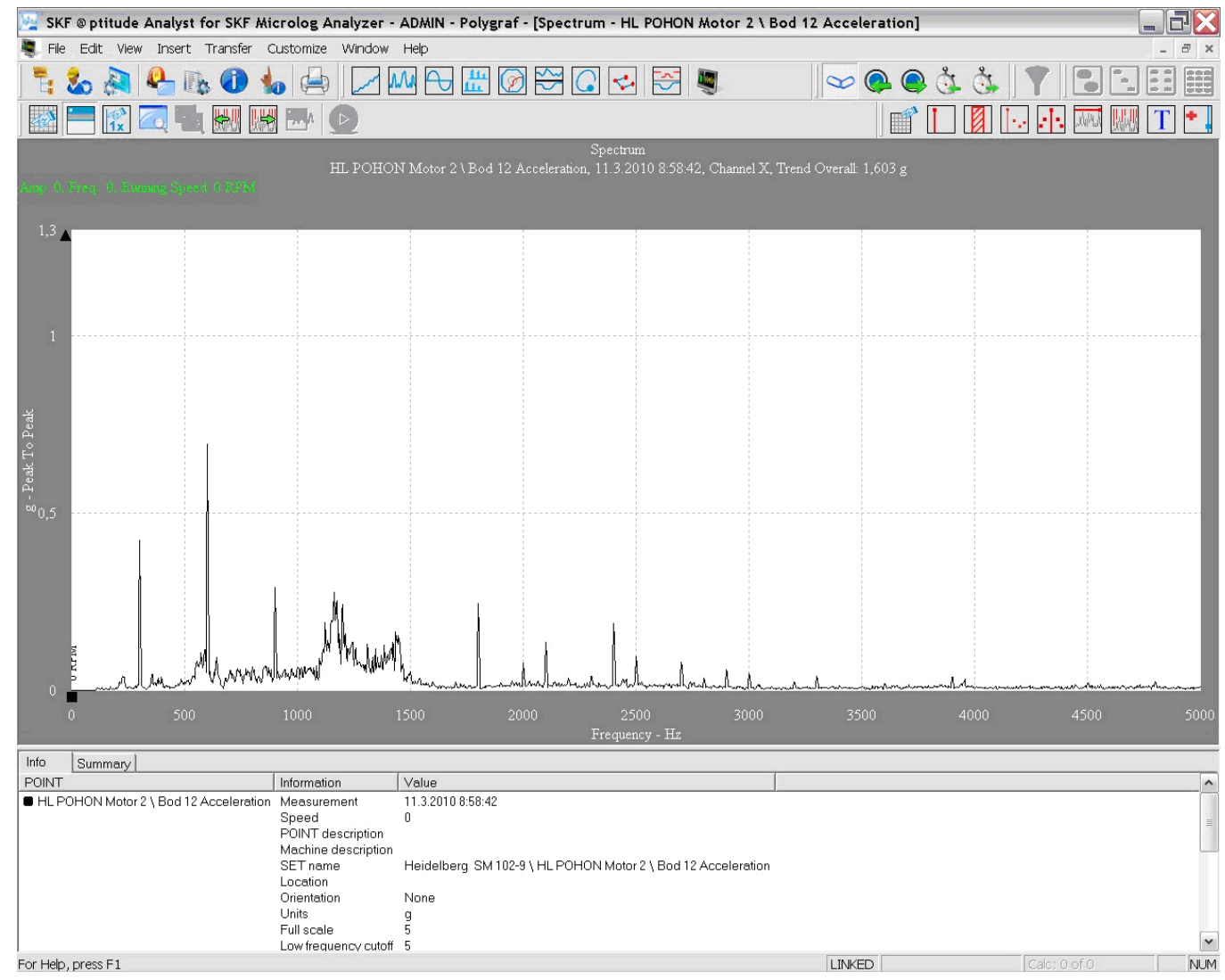

Fig. 10 Spectrum measured vibration diagnostic signals in the second measuring point at $3000 \mathrm{rpm}$ 


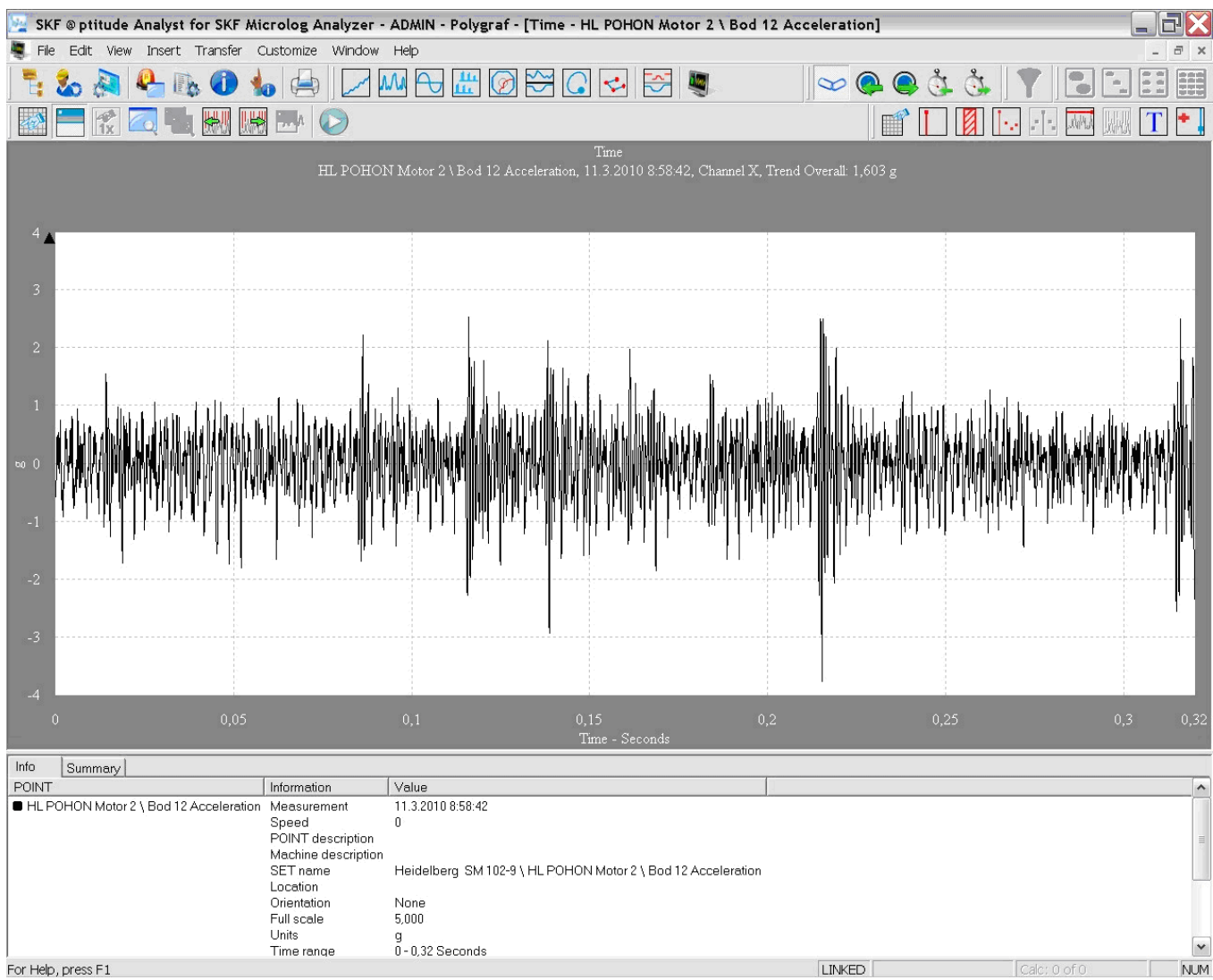

Fig. 11 Time recording the second measuring point at $3000 \mathrm{rpm}$

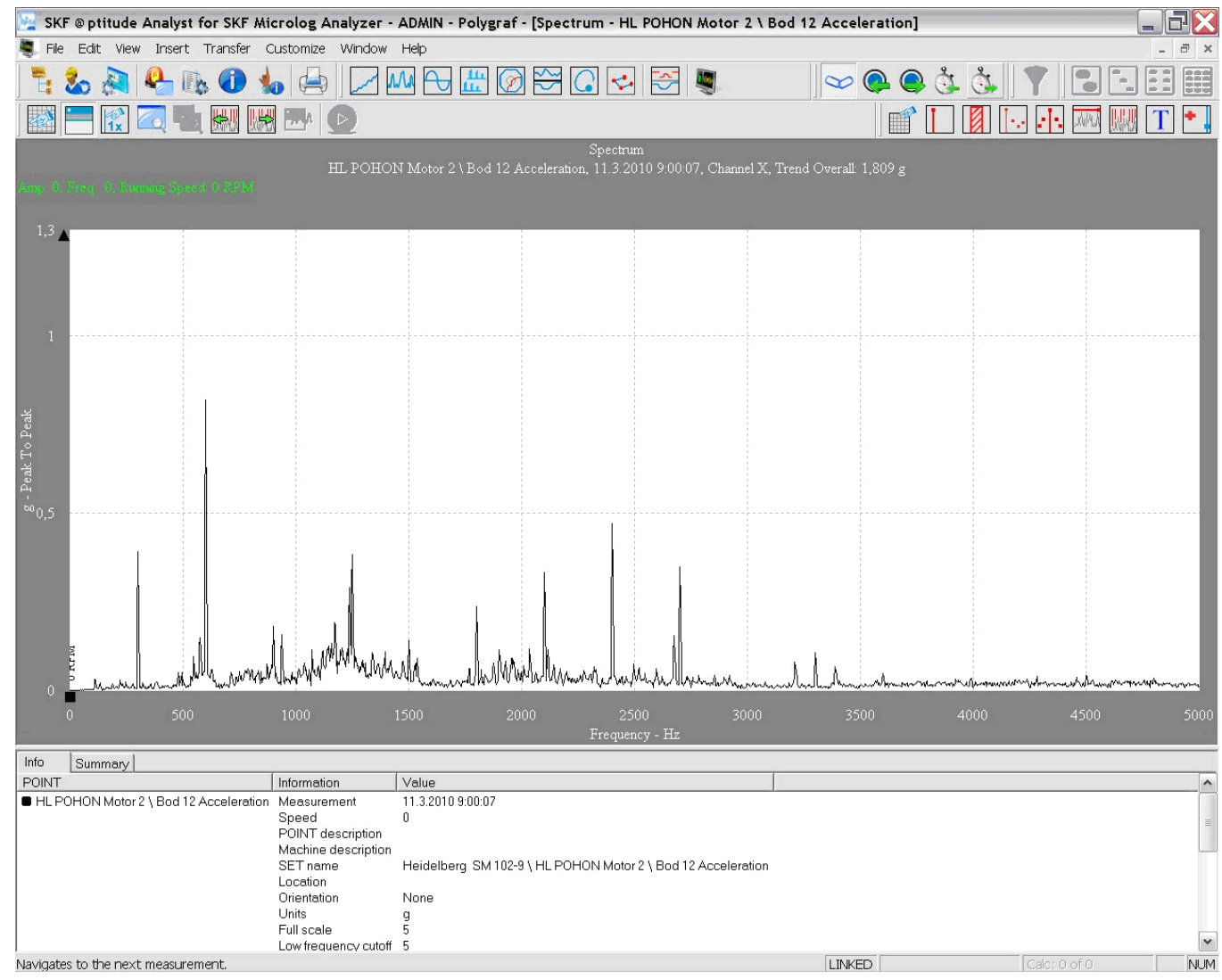

Fig. 12 Spectrum measured vibration diagnostic signals in the second measuring point at $8000 \mathrm{rpm}$ 


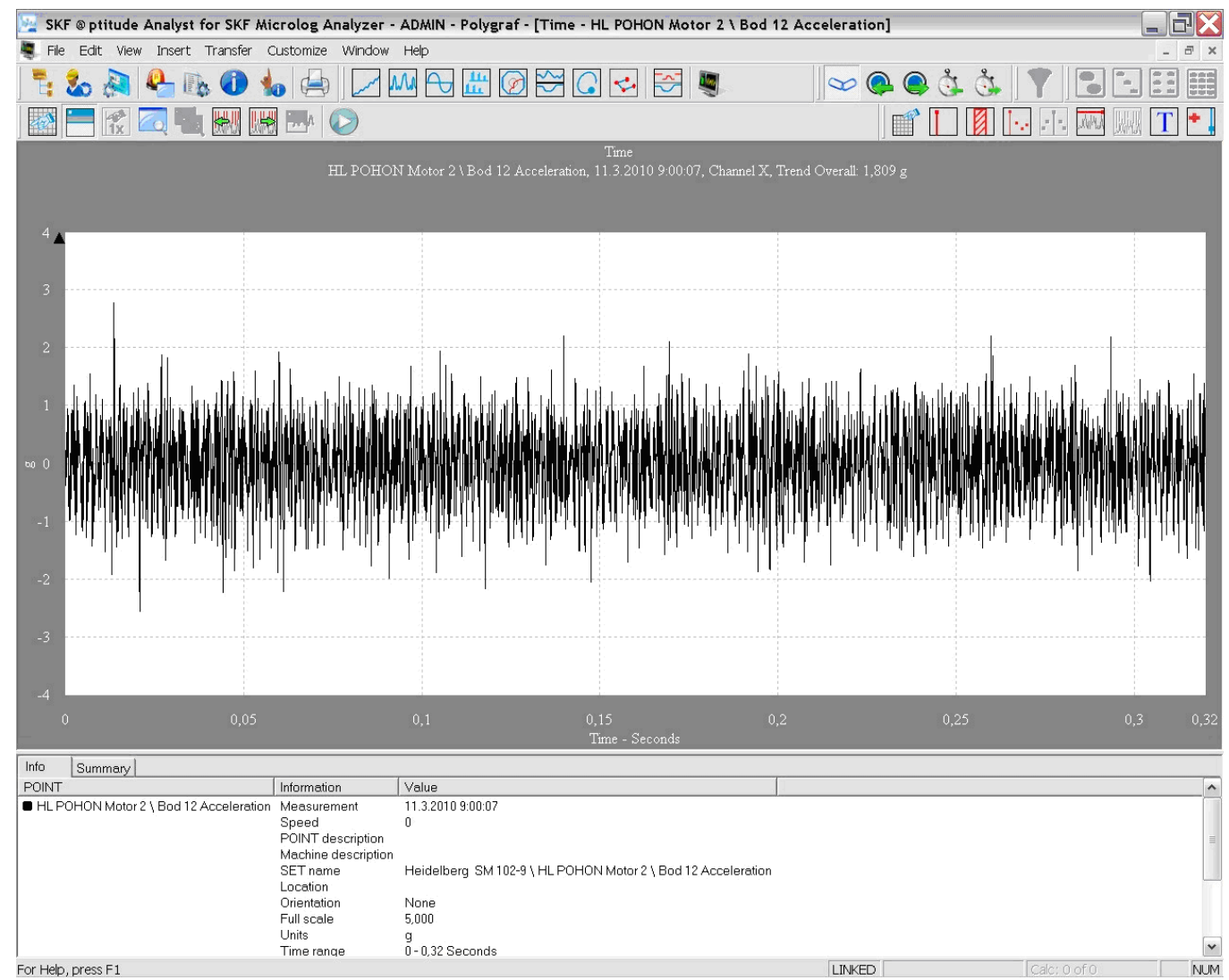

Fig. 13 Time recording the second measuring point at $8000 \mathrm{rpm}$

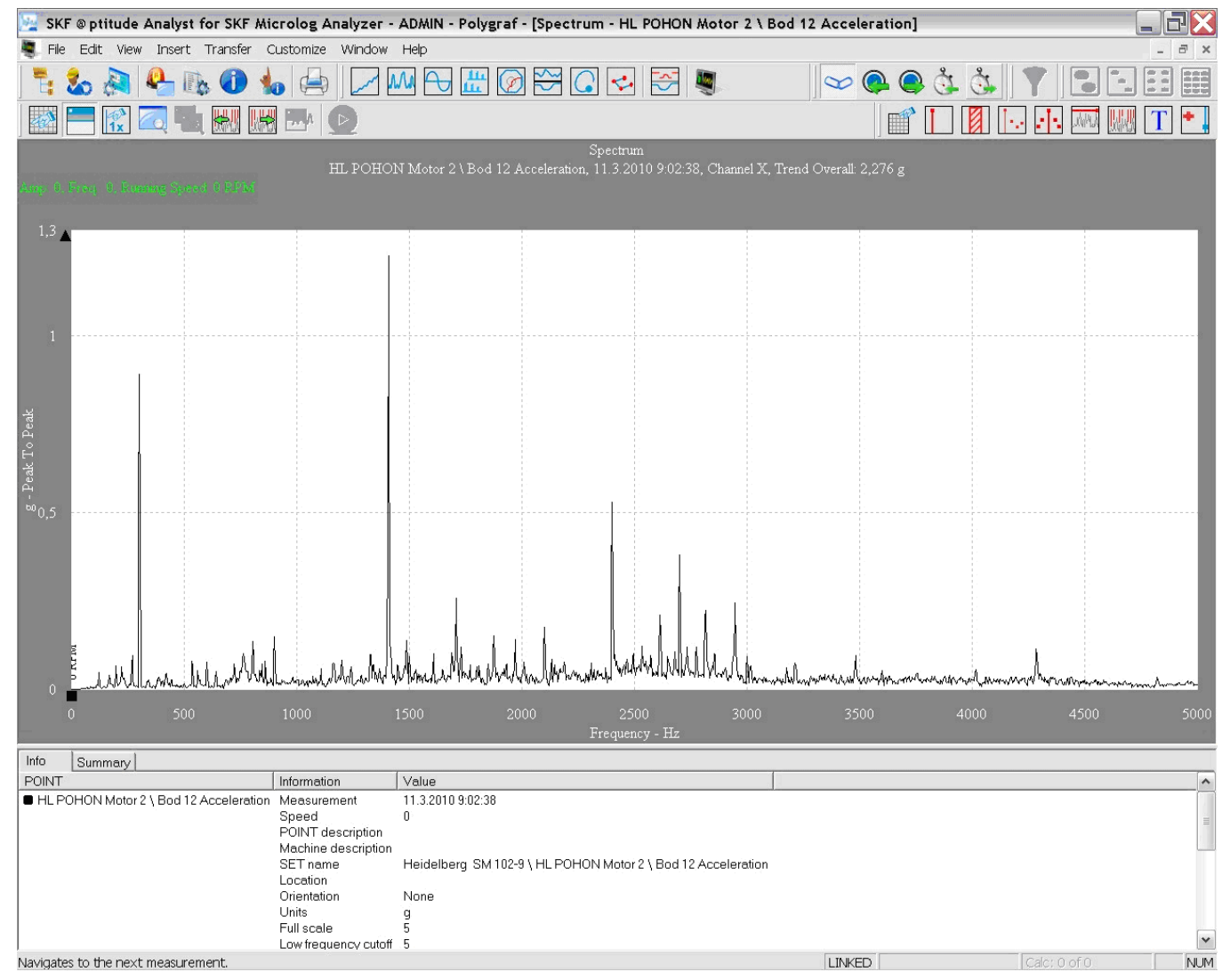

Fig. 14 Time recording the second measuring point at $12000 \mathrm{rpm}$ 


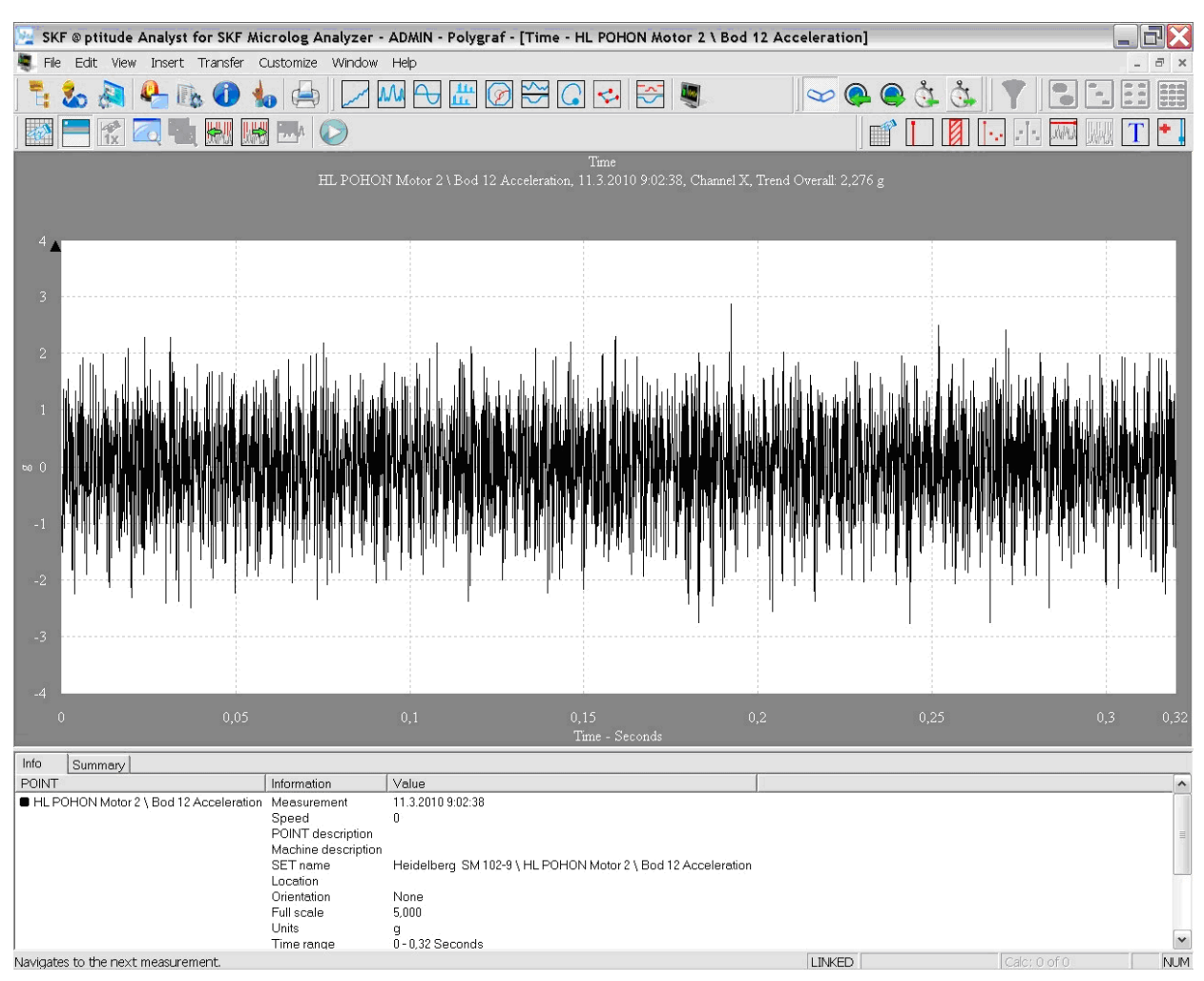

Fig. 15 Spectrum measured vibration diagnostic signals in the second measuring point at $12000 \mathrm{rpm}$

\section{Conclusion}

Vibration value measurements obtained had the following characteristics:

- The measurements were conducted for two measurement points and at 3000, 8000 and $12000 \mathrm{rpm}$.

- Acceleration value vibration is within the range of from zero to $1 \mathrm{~g}$. What for the machine according to the norm does not exceed the value vibration acceleration of $1.8 \mathrm{~g}$.

- Some acceleration value of the spectrum have a greater value in the lower frequency range, which gives information about possible impending failure and the impact of the release of structural parts of the machine.

- Although the record at the time showed values vibration acceleration greater than $1 \mathrm{~g}$ it is not reflected on the spectrum.

- The machine of the overall results of operations satisfy the requirements and can work in operation.

Article provides a basic overview and introduction to vibration diagnostics, as a method for early diagnosis of emerging faults diagnosed by analyzing machine vibration measurement on that device, because a major impact on production efficiency interoperability has just emerging early diagnosis of faults in the use of machinery and its effective removal. Practical measurements confirmed the assumptions of conduct disorder has the final shape of the measured disturbance variables depending on the type of disorder. That article analyzed the vibrations measured on the printing machine $\mathrm{He}$ Delberg (Speedmaster), year 1997, the country of origin, Germany. The measurement device was used microlog GX-S. The measurements were performed on a motor bearings Siemens entry and exit of the main printing machine operator. Given the objective identification and subsequent processing of the measured values of vibration diagnostic measurements are measured at three different speeds for input and output section. Reported values are analyzed on the basis of spectra and time records. These records were evaluated using the diagram. Measurement results showed deposits of perfection, even after many years of continuous operation of the machine with minimal maintenance. The aim of this course is to describe the practical diagnosis of the technical problems of a particular printing machine using vibration diagnostic measurements. Despite the fact that the said vibration diagnostic measurements show no technical failure to measure the printing machine is shown that such a diagnosis can be scheduled to avoid serious disturbances in machinery, which are often expensive and difficult to repair. Therefore, I propose that similar measurements carried out regularly in a certain time interval and thus could prevent unwanted downtime due to failure.

The main part of the research, investigation and analysis of vibration of the operating reliability and operational conditions of the production system, building models to simulate the vibration of the operating reliability and lower operating costs of the production system. The importance of vibration diagnosis is large, but even in its manufacturing plants not given importance. In collaboration with adequate maintenance can prevent vibration diagnostics of machinery malfunctions. Can we save not only money but also expensive machines. The vibration diagnostic methods used much. In practice this means that for each type of machine there is a separate method. The main task is to determine the vibration 
diagnostics moment when the bearing is the end of their life. The analysis and diagnosis of vibration of the justification given in practice to prevent damage to machine parts such as bearings and the like. Vibration diagnostics is performed by measuring the vibration and vibration of moving parts of machinery. To measure in practice using a variety of devices that capture the vibration spectrum over time.

\section{Acknowledgments}

This article was written within the project: K-14-008-00. This article was written within the project: ITMS project code: 26220220125; Operational Programme Research and Development support research activities

\section{References}

[1] Jacko, P., Krenicky, T. , Salokyova, S. and Rimar, M. Vibration detection technology heads in the process of cutting water jet, Strojarstvo extra 2011, 46 (2013) 1-3

[2] Orlovsky, I., Hatala, M. and Duplak, J. Balance equation - an essential element of the definition of thy drying process. Advanced Materials Research 2014, 849 (2013) 220-4

[3] Jurko, J., Panda, A., and Pandova, I. Analysis of the tool wear of screw drill during the drilling of steel X04CR16Ni12MnTiN. Applied Mechanics and Materials 2014, 599-601 (2014) 32-5

[4] Jurko, J., Džupon, M., Panda. A., Zajac, J., Study influence of plastic deformation a new extra low carbon stainless steels XCr17Ni7MoTiN under the surface finish when drilling, Advanced Materials Research 2012, 541 (2012) 1312 1315

[5] Čačko, P., Krenický, T., Dobranský, J., Impact of an excessive wear of bearing on the mechatronic devices, Applied Mechanics and Materials, 460 (2014) 99-106

[6] Gaspar, S., Pasko,. Influence of technological factors of die casting on mechanical properties of castings from siluin, In: Lecure Notes in Electrical Engineering. Vol. 240 (2013) 713-722

[7] Mascenik. J., Pavlenko, S., Bicejova, L.: Component selected parameters geometrical tolerance value experimental specification, Applied Mechanis and Materials 2013, 389 (2013) 1096-1099

[8] Straka, L., Rimar, M,. Corny, I. and Mihalcova, J. Increasing oc operational reliability of technical system. Paper presented at the Annals of DAAAM and Proceedings of the International DAAAM Smposium, (2011) 1089-1090

[9] Šmeringaiová, A., Valíček, J., Hloch, S., Goban, J.: Three views on kinematic analysis of crank mechanism in educational process. International Scientific Geoconference and EXPO, 3 (2011) 1309-1314.

[10] Novak-Marcincin, J., Fecova, V., Novakova- Marcincinova, L., Janak, M., Barna, J., Kocisko, M.: Virtools and its application in MOCAP and creation of the scripts for animations of models. Engineering Review 2012, 32 (2012) 96-102.

[11] Góts, I., Zajac, J., Vojtko, I.: Vorrichtung zum Messen des Abnutzungsgrades von Schneidwerkzeugen, Technisches Messen /carent/, 62 (1995) 8-11.

[12] Gašpár, Š., Maščenik, J., Paško, J.: The effect of degassing pressure casting molds on the quality of pressure casting, Advanced Materials Research. 428 (2012) 43-46.

[13] Straka, L.: Operational reliability of mechatronic equipment based on pneumatic artificial muscle. Applied Mechanics and Materials. 460 (2014) 41-8.

[14] Monkova, K., Monka, P.: Vibrodiagnostics and its application in manufacturing practice. Applied Mechanics and Materials 2013, 390 (2013) 220-4.

[15] Monkova, K., Monka, P.: Vibrodiagnostics and its application in manufacturing practice. Applied Mechanics and Materials 2013, 390 (2013) 220-224.

[16] Vagaská, A.: Mathematical description and static characteristics of the spring actuator with pneumatic artificial muscle. Applied Mechanics and Materials 2014, 460 (2014) 65-72.

[17] Svetlík, J., Baron, P., Dobránsky, J., Kočiško, M.: Implementation of computer system for support of technological preparation of production for technologies of surface processing. Applied Mechanics and Materials 2014, 613 (2014) 418-25.

[18] Salokyová, Š, Jacko, P., Rimár, M.: Effect of grain size and type of abrasive spectrum of vibration acceleration in the process of water jet cutting, 5 (2011) 39/1-39/4.

[19] Fedak, M, Semanco, P, Micko, M.: Statistical process control method based on weight percent of al-si alloy for melting and holding process in die casting. Lecture Notes of the Institute for Computer Sciences, Social-Informatics and Telecommunications Engineering 2012, 62 (2012) 188-90.

[20] Vojtko, I., Simkulet, V., Baron, P., Orlovský, I.: Microstructural characteristics investigation of the chip-making process after machining. Applied Mechanics and Materials 2014, 616 (2014) 344-50. 